\title{
Dampak Strategi Penjualan Dan Pengembangan Produk Terhadap Minat Beli
}

\author{
Sonia Ritonga ${ }^{1}$, Nuri Aslami² \\ Program Studi Asuransi Syariah, Fakultas Ekonomi dan Bisnis Islam, \\ Universitas Islam Negeri Sumatera Utara, Medan, Indonesia \\ Email: ${ }^{1}$ soniaritonga024@gmail.com, ${ }^{2}$ nuriaslami@uinsu.ac.id
}

\begin{abstract}
This research is motivated by the not yet optimal application of marketing strategies, namely, company's competitive position and economic situation. In addition, product development has not everything is processed with the help of machines so it takes quite a long time in producing it. This study uses a descriptive analysis design. Amountpopulation that will be the object of research is the existing consumers in PD. Original Taste namely 3,106 person. The following method of unifying the observation files is study literature, field studies (observations, interviews and questionnaires). Data analysis stages starting with validity, reliability, interval value transformation, and data analysis verification/quantitative. The results of the study show that: 1) Marketing strategy has a relationship with buying interest in PD. Ciamis Original Taste with correlation test results of 0.789 which has a strong relationship level, with an influence level of 62.19\%; 2) product development has a relationship with consumer buying interest with test resultscorrelation of 0.778 which has a strong relationship level, with a level of influence of 60.60\%; 3) Marketing strategy and product development have a relationship with interest consumer buying in PD. Original Taste of Ciamis with a correlation test result of 0.914 which has the relationship level is very strong, with an influence level of $83.54 \%$.
\end{abstract}

Keywords: Marketing Strategy, Product Development, Buying Interest.

\begin{abstract}
Abstrak
Observasi ini merupakan motif karena belum maksimalnya pemakaian trik penjualan yakni keadaan pertarungan perusahaan serta keadaan perdagangan. Bersama dengan, peningkatan barang masih seluruhnya dioperasikan lewat pertolongan bukan manual maka membutuhkan durasi agak sedikit panjang untuk menciptakannya. Observasi berikut memanfaatkan cara elaborasi penguraian. kumpulan mengenai sasaran objek observasi ialah pelanggan yang posisinya berada di PD. Rasa asli yakni sebesar 3.106 jiwa. Metode pemungutan data pada observasi berikut ialah belajar kepustakaan, belajar lapangan (penelitian, interviu serta kuesioner). Jenjang obsevasi data berawal lewat tes fondasi, integritas, perubahan poin interval, juga observasi data melalui berdasarkan jumlah dan banyaknya. Hasil observasi ditemukan dimana: 1.) trik penjualan mempunyai kaitan lewat hasrat beli di PD. Rasa Asli Ciamis lewat hasil tes interelasi sebanyak 0,789 dimana mempunyai posisi keterkaitan yang besar, lewat tajuk otoritas sebanyak 62,19\%; 2peningkatan barang mempunyai ketertarikan lewat hasrat beli pelanggan lewat hasil tes interelasi sebanyak 0,778 dimana mempunyai keterkaitan yang besar, melalui tajuk dampak sebanyak 60,60\%; 3.) trik penjualan serta peningkatan barang mempunyai ketertarikan melalui hasrat beli pelanggan di PD. Rasa
\end{abstract}


Asli Ciamis melalui hasil tes interelasi sebanyak 0,914 dimana mempunyai tajuk keterkaitan kuat, melalui tingkat pengaruh sebanyak 83,54\%.

Kata kunci: Strategi Pemasaran, Pengembangan Produk, Minat Beli.

\section{PENDAHULUAN}

Seiring melalui perkembangan perdagangan serta peningkatan teknologi, sampai dunia bisnis akan mengalami perubahan yang cepat lewat timbulnya bermacam-macam perusahaan yang berjuang membuat barang serta jasa untuk memenuhi kebutuhan serta keinginan konsumen. Peningkatan pesat dalam dunia usaha dan menyampaikan gambaran mengenai kesejahteraan masyarakat yang bertambah berkembang, kesejahteraan yang berkembang berikut untuk menambah pula kemampuan beli masyarakat maupun pelanggan. Namun saat waktu peningkatan tersebut membawa dampak munculnya persaingan yang bertambah kuat di dunia bisnis yang matang tersebut.

Perusahaan sewaktu awalnya mempunyai bagian tempat cukup besar ini, juga kawasan penjualan cukup luas, saat ini dituntut dalam bekerja lebih terperinci juga tepat dalam melaksanakan strategi pemasaran dan pengembangan produk dalam menunjang kelangsungan hidup perusahaan semakin penting juga reaktif menghindari pasar yang hendak mereka masukk baik sekarang juga pada waktu yang hendak datang. Peningkatan materi juga teknologi yang benar-benar pesat di bopong oleh fasilitas yang mencukupi mendorong penciptaan produk-produk baru yang lebih menarik.

Pada PD. Rasa Asli Ciamis selaku perusahaan industri makanan semacam galendo dalam strategi pemasaran dan pengembangan produknya masih belum maksimal, strategi pemasaran yang digunakan dengan sistem mempromosikan produk ke masyarakat umum, salah satu caranya iala membuat outlet penjualan sekedar di daerah Ciamis belum berkembang sampai ke luar Kota sehingga masih banyak yang tidak mengetahui mengenai produknya.

Sementara dalam pengembangan produk belum seluruhnya diproses dengan memanfaatkan jasa mesin sehinga masih membutuhkan jangka yang tidak sebentar dalam memproduksinya. Maka dari itu mestinya perusahaan khusunya manajer pemasaran lebih mengkaji dan paham betul dalam strategi pemasaran yang benar agar perusahaan bisa di kenal lebih luas dan profit yang dihasilkan akan lebih maksimal.

PD. Rasa Asli yang serupa dengan produk galendo sebagai buah tangan khas ciamis namun bukan hanya galendo saja yang dihasilkan melainkan memproduksi minyak kelapa sebagai penjualannya juga. Tempat outlet pemasarannya benar-benar strategis namun pelanggan sedikit datang yang berdampak kelihatan sunyi dihari biasa, keberadaan banyak pelanggan sewaktu liburan saja. Selain itu unsur cuaca juga mempengaruhi dalam penjualannya karena kebanyakan konsumen biasanya wisatawan. Kebanyakan dari konsumen yang masih pemula membeli juga tidak begitu memperhatikan pelayanan. pelanggan yang datang membeli gagal menjamin agar datang lagi sebab mereka cuma singgah membeli buah tangan kepada keluarga.

Salah satu yang perlu diterapkan oleh PD. Rasa Asli ialah promosi dan peningkatan barang, inti dari kegiatan promosi ialah salah satu bentuk kegiatan komuunikasi penjualan yang berupaya menyalurkan informasi, mempengaruhi, mengingatkan pasar 
sasaran supaya bersedia menerima dan membeli sedangkan pengembangan barang yaitu menambah kualitas produk yang dihasilkan sehingga seandainya perusahaan bisa mengimplementasikan strategi pemasaran dan meningkatkan pengembangan produknya yang cocok di dalam perusahaan, maka dipastikan penjualan perusahaan akan naik.

Setiap kawasan usaha buah tangan sudah melaksanakan promosi semacam memberikan penawaran produk untuk konsumen dengan melaksanakan pengembangan produk supaya memukau minat beli konsumen. namun konsumen sedikit yang tertarik untuk membeli produknya. tarif yang ditawarkan penjual terhadap kawasan nyaris sama juga bisa ditawar. barang Galendo menawarkan tarif yang bisa terjual terhadap bagian menengah kebawah.

Menurut data penjualan perusahaan PD. Rasa Asli Ciamis, kuantitas penjualan pada tahun 2012 hingga tahun 2016, sejak tahun ke tahun mengalami peningkatan dan cuma pada tahun 2015 yang mengalami penyusutan karena faktor dari minimnya strategi pemasaran yang dilaksankan, lebih tepatnya dapat dilihat data dibawah ini:

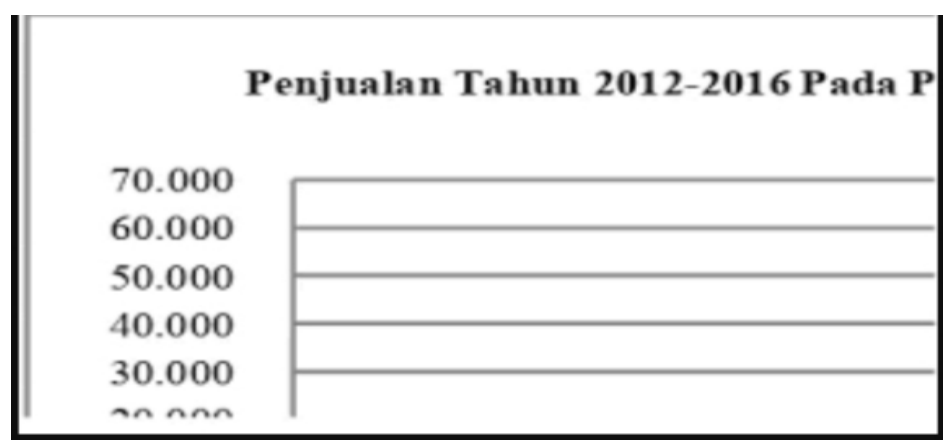

Gambar 1. Data Penjualan Tahun 2012-2016 PD. Rasa Asli

Berdasarkan data tersebut dapat dilihat bahwa tahun 2012 memperlihatkan penjualan sebanyak 54.200 pcs, lalu naik sebanyak 55.150 pcs pada 2013, kemudian kembali meningkat sebanyak 63.630 pcs pada 2014, peningkatan ini disebabkan perusahaan sudah melaksanakan pengembangan produknya dengan menganalisis kebutuhan pelanggan, pemunculan gagasan, penyaringan ide, analisis bisnis dan melakukan pengembangan produk. Sedangkan pada tahun 2015 mengalami penyusutan penjualan sebanyak 43.752 pcs yang disebabkan perusahaan belum optimal dalam melaksanakan strategi pemasaran salah satunya penetapan pasar sasaran dan penetapan keadaan pasar tetapi pada tahun 2016 mengalami kenaikan penjualan kembali sebanyak 66.445 pcs karena perusahaan mulai mengoptimalkan strategi pemasaran dengan meningkatkan pembagian pasar dan menganalisis kawasan pasar, terutama pesaing juga menambah kualitas produk lebih unggul dibandingkan pesaing.

\section{Permasalahan}

1. Bagaimana dampak strategi pemasaran terhadap minat beli pada PD. Rasa Asli?

2. Bagaimana dampak peningkatan barang akan hasrat beli pada PD. Rasa Asli?

3. Seberapa besar dampak skema penjualan serta peningkatan barang terhadap hasrat belanja pada PD. Rasa Asli?

\section{KAJIAN TEORI}


Trik penjualan menurut pendapat Philip Kotler ialah bentuk di mana tugas pedagang mengelola pekerjaannya agar memproleh perkembangan yang bermanfaat ketika pemasaran saat tajuk perpaduan penjualan. (Kotler) trik penjualan ialah salah satu segaris pendapat juga gambaran ide ketika penjualan buat digunakan agar mendapatkan wujud pemasaran. Pada gambaran ide ini terdapat trik spesifik tentang tujuan pasar maupu objek penjualan, yang mana letaknya, perpaduan juga taksiran untuk penjualan.

Isi bukunya yang berjudul "Marketing Strategy", Robert W. Palmatier dan Shrihari Sridhar menerangkan tentang trik penjualan ialah materi yang terdiri dari keputusan juga kelakuan yang dititik terangkan terhadap membangun keunggulan diferensial yang berkelanjutan, relatif akan pesaing, pada hati pelanggan, untuk menciptakan nominal bagi pemangku kepentingan.

Kotler serta Amstrong, saat 2008 mendeskripsikan makna dari trik penjualan ialah sebuah kekuatan pikir terhadap penjualan yang merupakan salah satu upaya (usaha) eksklusif memngandalkan sebuah poin baik juga profit lewat gambaran keterkaitan melalui pemakai maupun pelanggan.

Kurtz, strategi penjualan ialah kegiatan yang sepenuhnya oleh perusahaan ketika usaha memastikan intense penjualan juga agar menyenangkan pelanggan. Cara ini dibuat lewat membuat konsolidasi maupun sinkronisasi melalui barang-barang yakni barang, promosi, penjualan mix, peredaran serta tarif.

Stanton, trik pemasaran serta marketing ialah salah satu program yang mana dijumpai adanya keterkaitan disela-sela wujud ancang-ancang serta penetapan tarif melalui seperti apa menawarkan juga mengungkapkan serta menyebarkan barang baik produk maupun jasa untuk pelanggan (pengguna).

\section{METODE PENELITIAN}

\subsection{Metode Penelitian yang Digunakan}

Metode yang dipakai terhadap observasi tersebut ialah metode deksriptif analisis, sebab dilakukan melalaui cara systematic, aktual, dan akurat mengenai fakta atau objek juga menginterprestasikan keterkaitan antara fenomena yang diselidiki.

Menurut Sukmadinata, (2011), ada beberapa berbagai dalamm observasi deskriptif yakni belajar peningkatan, belajar kasuss, belajar kemasyarakatan, belajar perundinganan, belajar keterkaitan, belajari waktuu serta gerakk, belajar lanjut, belajar kecenderungan, observasi kegiatan serta observasi maupun dokumen.

\subsection{Sumber dan Teknik Pengumpulan Data.}

sistem pengambilan data ketika observasi ini yaitu dengan belajar kesusastraan, belajar lapangan (pengamatan, interviu serta kusioner jajak pendapat). jenjang analogi data sejak melalui tes kebenaran, reabilitas, perubahan poin interval, serta analisis data dengan kognitif.

\subsection{Teknik Analisis Data}


Dalam observasi tersebut mencoba mendeskripsikan serta menginterpretasikan ikatan antara variable berlandaskan data serta informasi yang membantu setakar lewat karakter, permasalahan serta tujuan dilaksanakannya observasi. berdasarkan data inforrmasi yang dikumpulkan penulis melaksanakan bermacam jenis guna mencapai kesimpuulan. observasi dilaksanakan melalaui menggunakan pendekatan kuantitatif.

\section{HASIL DAN PEMBAHASAN}

\subsection{Dampak Strategi Pemasaran Akan Hasrat Beli Konsumen pada PD. Rasa Asli Ciamis}

Pemasaran ialah salah satu pelaksanan lewat memperkenalkan suatu perusahaan serta barangnya supaya bisa diingat olehh masayarakat serta menggunakan produk juga jasa melalui perusahaan.

Trik penjualan ialah tahap sosial yang didalamnya individu maupun kelompok mendapatkan apa yang merekaa perlukan serta inginkan melalui menciptakan, menawarkan serta mempertukarkan barang serta jasa yang bernilai melalui pihak lain.

Hal ini searah terhadap pendapat Kotler (2009: 401) yang mengungkapkan bahwa: trik penjualan yaitu pendekatan utama yang bakal dipakai olehh bisnis untuk mendapatkan tujuan yang telah di atur di awal; didalamnya terdapat keputusan-keputusan dasar tentang pencapaian pasarr, kedudukan barang di pasar, bauran penjualan serta tajuk tarif penjualan yang dibutuhkan yang bisa berpengaruh terhadap hasrat beli pelanggan.

karena pendapat di atass, maka bisa disimpulkaan bahhwa trik penjualan bisa merubah hasrat beli pelanggan. karena begitu jika trik penjualan yang dilaksanakan bagian perusahaan berjalan dengaan efektif maka minat beli pelanggan bisa naik.

Indikator yang dipakai dalam variabel strategi pemasaran yaitu: 1) Segmentasi (segmentation); 2) Penetapan pasar sasaran (Targeting); 3) Penetapan posisi pasar (Positioning). Hasil penelitian memperlihatkan bahwa strategi pemasaran diPD. Rasa Asli Ciamis ialah baik dengan jumlah skor 3797.

Teori tersebut sejalan dengan hasil observasi ditemukan bahwa trik penjualan berdampak terhadap ketertarikan belanja konsumen di PD. Rasa Asli Ciamis akibat percobaan kesessuaian sebanyak 0,789 yang mempunyai tajuk hubungan yang besar, melalui tajuk otoritas sebanyak $62,19 \%$ yang artinya bahwa strategi pemasaran berdampak terhadap minat beli sebanyak 62,19\%. Kegiatan ini satu arah lewat kesimpulan dari tes asumsi dilihat bahwa interelasi bisa diucapkan fisis jika $t$ hitung $>\mathrm{t}$ diagram hasil penjumlahan tersebut melalui $\square$ (alpa) buat tes 2 sisi juga $\mathrm{dk}=\mathrm{n}-2$ (95) didapatkan mutu t taksir $=12,505$ sementara mutu t diagram $=1,999$. Maka kesimpulan dari perkiraan bahwasanya strategi pemasaran berdampak akan minat beli konsumen.

4.2 Dampak Peningkatan Barang Akan Hasrat Beli Konsumen Di PD. Rasa Asli Ciamis 
Pengembangan produk dapat memberikan dampak akan hasrat beli pelanggan sama jika bertambah baik penerapan pengembangan barang maka hasrat pelanggan bisa bertambah baik.

Hal tersebut sejalan dengan yang dikemukakan oleh pendapat Crocc, (2000: 126) bahwa: "Peningkatan barang yakni sebuah kegiatan dimana diawali melalui observasi kesan juga waktu. Peningkatan barang ialah kegiatan rute positif dimana memerlukan donasi sejak nyaris seluruh tugas yang terdapat pada perusahan".

Sementara pendapat Kotler (2000: 374) bahwa: setiap perusahaaan wajib meningkatkan barang baru. Peningkatan barang baru membuat masaa depaan perusahaan. barang pengganti wajib dibuat guna mempertahankan atau membangun pemasaran. Perusahaan bisa menambahh barang baruu lewat akuisisi serta ppeningkatan barang baru, dengat begitu maka minat konsumen akan meningkat.

Dengan begitu bisa disimpulkan bahwa perwujudan pengembangan produk yang dilaksanakan oleh suatu perusahaan akan semakin meningkatkan minat konsumen, sebab dengan adanya pengembangan produk maka impian konsumen bisa terjalankan. Indikator yang digunakan dalam variabel pembagian kerja yakni:

1) Analisis Kebutuhan pelanggan

2) Pemunculan gagasaan

3) Penyaringan Ide

4) Observasi Bissnis

5) Peningkatan Strategi Penjualan

6) Pengembangan Barang

7) Pengujian Produk dan Pasar dan

8) Komersialisasi.

Hasil penelitian memperlihatkan pengembangan produk di PD. Rasa Asli Ciamis adalah baik dengan jumlah skor 3205 .

Teori tersebut searah dengan akhir observasi didapati dimana pengembangan produk berdampak akan hasrat beli pelanggan melalui hasil tes interasi sebanyak 0.778yang mempunyai tajuk jalinan besar, lewat tajuk dominasi sebanyak 60,60\% sama maknanya pengembangan produk berdampak lewat hasrat beli pelanggan sebanyak 60,60\%. dimana satu arah lewat hasil tes tesis didapati dimana interelasi bisa diucapkan substansial jika t dikira>t diagram hasil penjumlahan lewat $\square$ guna tes dua bagian juga $\mathrm{dk}=\mathrm{n}-2$ (95) didapatkan mutu $\mathrm{t}$ dikira $=12,089$, dimana mutu t tabel $=1,999$. Maka akhir penjumlahan ternyata pengembangan barang berdampak akan hasrat beli pelanggan.

\subsection{Dampak Trik Penjualan dan Peningkatan Barang terhadap Hasrat Beli Pelanggan pada PD. Rasa Asli Ciamis}

Hasrat ialah fase kecenderungan responden agar berbuat sebelum kepuutusan membeli segenap hati dilakukankan. dijumpai perbedaan aantara pemmbelian aktual dan minat pembelian. Jika pembelian aaktual ialah pemmbelian yang berul-betul dilaksanakan olehh pelanggan, maka hasrat pembelian ialah niat guna melaksanakan pembelian pada kesempatan di kemudian hari. Walaupun biasanya pembelian yang belumm pasti bakal dilaksanakan paada waktu yang aakan datang, akan tetapi pengukuran terhadap hasrat 
pembelian umumnya dilaksanakan untuk memaksimalkan perkiraan akan pembeliaan aktual tersebut. Supaya mendapatkan gambaran yang jelaas terhadap perlakuan pelanggan, di bawah ini aakan ditampilkan makna hasrat beli menurutt beberapaa penulis.

Hasrat beli ialah bagian terhadap unsur kepribadian pelanggan sebagai sikap mengkonsumsi, kecenderungaan respondenn untuk berbuat sebelum keputusan membeli betul-betul dilaksanakan.

Hal tersebut sepemikiran dengan pendapat Assael (2001: 24), mendeskripsikan hasrat beli menjadi "mengarahkan pelanggan agar membeli salah satu label maupun melakukan perbuatan yang berurusan terhadap pembelian yang dihitung melalui tajuk kesempatan pelanggan dalam proses pembelian”.

Sedangkan Simamora berpendapat (2004 : 98) berpendapat bahwa: Pengembangan produk dan strategi pemasaran sama-sama mempengaruhi minat konsumen, dengan adanya pengembangan produk yang baik dan strategi pemasaran yang dilakukan dengan tepat dan dapat menyampaikan informasi yang jelas maka akan mempengaruhi minat dan keputusan konsumen.

Indeks yang digunakan dalam variabel minat beli ialah: 1) Hasrat transaksionaal; 2) Minat refrensial; 3) Hasrat preferensiall serta 4) Hasrat eksploratiff. Hasil penelitian memperlihatkan minat beli pelanggan di PD. Rasa Asli Ciamis adalah bagus lewat poin 3550. Dari hasil penelitian diketahui bahwa trik penjualan serta peningkatan barang berkaitan dengan hasrat beli konsumen di PD. Rasa Asli Ciamis melalui hasil tes korelasi sebanyak 0,914 yang mempunyai tajuk keterikatan benar-benar kuatt, melalui tajuk pengaruh berdampak sebanyak $83,54 \%$ yang bermakna yang mana trik penjualan serta peningkatan barang mempunyai ikatan lewat keinginan beli pelanggan di PD. Rasa Asli Ciamis sebanyak 83,54\%. mengenai tersebut searah lewat hasil tes asumsi didapati dimana hubungan dapat diucapkan substansial sekiranya Fdikira> Fdiagram hasil penjumlahan tersebut ditemukan mutu Fhitung111,05\% dimana mutu Fdiagram= pada 0.05 juga $\mathrm{dk}=97-2-1=94$ ditemukan $\mathrm{F}$ table 3,09. Maka hasil Fhitung $>$ dari poini tabel. Berlandaskan dari hasil penjumlahan terlihat strategi pemasaran juga pengembangan barang berdampak signifikan akan hasrat beli pelanggan pada PD. Rasa Asli Ciamis. Berarti hipotesis yang diajukan dapat diterima/terbukti kebenarannya.

\section{PENUTUP}

Berlandaskan dari hasil observasi juga keterangan bahwa

1. Dijumpai dampak baik strategi pemasaran akan ketertarikan konsumen di PD. RasaAsliu Ciamis, yaitu apabila strategi pemasaran yang dilaksanakan tidak buruk lalu peminat beli pelanggan bakal naik.

2. Dijumpai dampak baik pengembangan barang akan peminat beli konsumen di PD. Rasa Asli Ciamis. yaitu apabila peningkatan produk yang dilaksanakan tidak buruk lalu minat beli konsumen bakal naik.

3. Dijumpai dampak baik strategi pemasaran juga pengembangan barang akan minat beli konsumen. yaitu apabila strategi pemasaran dan peningkatan produk yang dilaksanakan sudah benar maka peminat beli pelanggan bakal naik.maka tesis yang diutarakan tidak ditolak/terbukti kepastiannya 


\section{DAFTAR RUJUKAN}

Fitruiani, Fitriah. (2017). pengaruh strategi pemasaran dan pengembangan produk terhadap minat beli. Jurnal ilmu manajemen, vol.4 No.2, 2 oktober 2017.

Djaslim Saladin, Herry Achmad Buchory. (2010). Manajemen Pemasaran (Teori, Aplikasi dan Tanya Jawab). Bandung: Linda Karya, 2010

Arikunto, Suharsimi. (2010). Manajemen Penelitian Edisi Revisi. Jakarta: Rineka Cipta, 2010.

Budianto, Apri. (2015). Manajemen Pemasaran Edisi Revisi. Yogyakarta: Ombak, 2015.

Gregorius, Chandra. (2005). Strategi dan Program Pemasaran. Yogyakarta: ANDI, 2005 .

Handoko, T. Hani. (2003). Manajemen Edisi Kedua. Yogyakarta: BPFE

Kotler, Philip dan Gary Amstrong. (2006). Prinsipprinsip Pemasaran. Erlangga

Kotler, Philip dan Keller, Kevin Lane. (2007). Manajemen pemasaran edisi kedua belas jilid 1. : PT. INDEK 